\title{
Intensive insulin treatment reduced mortality and morbidity in critically ill patients
}

Van den Berghe G, Wouters P, Weekers F, et al. Intensive insulin therapy in critically ill patients. N Engl J Med 2001 Nov 8;345:1359-67.

\section{QUESTION: In patients who are critically ill, does normalisation of blood glucose concentrations with intensive insulin treatment reduce mortality and morbidity?}

\section{Design}

Randomised (allocation concealed), blinded (patients, outcome assessors), controlled trial \{with mean follow up of 23 days $\}^{*}$.

\section{Setting}

Surgical intensive care unit (ICU) at the university hospital in Leuven, Belgium.

\section{Patients}

1548 patients (mean age $63 \mathrm{y}, 71 \%$ men) admitted to the ICU who were receiving mechanical ventilation. Patients were excluded if they were participating in other trials, were moribund, or had "do not resuscitate" orders. Follow up was $100 \%$.

\section{Intervention}

Patients were assigned to receive intensive $(n=765)$ or conventional $(n=783)$ insulin treatment. Intensive treatment was insulin infusion that was started if the blood glucose concentration was $>6.1 \mathrm{mmol} / \mathrm{l}$, and was adjusted to maintain a blood glucose concentration of 4.4-6.1 mmol/1 (maximum insulin dose $50 \mathrm{IU} / \mathrm{h}$ ). Conventional treatment was continuous insulin infusion by a pump that was started if the blood glucose concentration was $>11.9 \mathrm{mmol} / \mathrm{l}$ and adjusted to maintain a blood glucose concentration between 10.0 and $11.1 \mathrm{mmol} / \mathrm{l}$. All patients were fed continuous intravenous glucose upon ICU admission. Total parenteral, combined parenteral and enteral, or total enteral feeding was started the next day. Total enteral feeding was attempted as early as possible.

\section{Main outcome measures}

The primary outcome measure was all cause death in the ICU. Secondary outcome measures included in hospital death, length of ICU stay, need for ICU care or ventilatory support $>14$ days, and various complications of the critical illness.

\section{Main results}

Analysis was by intention to treat. Intensive insulin treatment had reduced rates of all cause ICU deaths among all patients $(\mathrm{p}<0.04)$ and among those who were in the ICU $>5$ days $(\mathrm{p}=0.005)$; in hospital deaths $(\mathrm{p}=0.01)$; ICU care $>14$ days $(\mathrm{p}=0.01)$; ventilatory support $>14$ days $(\mathrm{p}=0.003)$; renal failure requiring dialysis or haemofiltration $(\mathrm{p}=0.007)$; bloodstream infections in the ICU ( $\mathrm{p}=0.003)$; and critical illness polyneuropathy $(\mathrm{p}<0.001)$ (table). The groups did not differ for length of ICU stay (median $3 \mathrm{~d}$ in both groups, $\mathrm{p}=0.2$ ).

\section{Conclusion}

In patients who were critically ill, normalisation of blood glucose concentrations with intensive insulin treatment reduced mortality and morbidity.

*Information provided by author.

Intensive v conventional insulin treatment in critically ill patients $\dagger^{\dagger}$

\begin{tabular}{|c|c|c|c|c|}
\hline $\begin{array}{l}\text { Outcomes at mean follow } \\
\text { up of } 23 \text { days }\end{array}$ & Intensive & Conventional & $\operatorname{RRR}(95 \% \mathrm{Cl})$ & NNT (Cl) \\
\hline All ICU deaths & $5 \%$ & $8 \%$ & $43 \%$ (15 to 62$)$ & $29(17$ to 94$)$ \\
\hline All in hospital deaths & $7 \%$ & $11 \%$ & $34 \%(9$ to 52$)$ & 27 (15 to 122$)$ \\
\hline ICU stay $>14$ days & $11 \%$ & $16 \%$ & $28 \%(7$ to 44$)$ & $23(13$ to 108$)$ \\
\hline Ventilatory support $>14$ days & $8 \%$ & $12 \%$ & $37 \%(14$ to 54$)$ & 23 (14 to 67$)$ \\
\hline $\begin{array}{l}\text { Renal failure requiring } \\
\text { dialysis or haemofiltration }\end{array}$ & $5 \%$ & $8 \%$ & $41 \%(13$ to 60$)$ & 30 (17 to 112$)$ \\
\hline Bloodstream infection & $4 \%$ & $8 \%$ & $46 \%(19$ to 65$)$ & 28 (17 to 79$)$ \\
\hline $\begin{array}{l}\text { Critical illness } \\
\text { polyneuropathy }\end{array}$ & $29 \%$ & $52 \%$ & $45 \%$ (28 to 59$)$ & 4 (3 to 8$)$ \\
\hline
\end{tabular}

†ICU = intensive care unit. Other abbreviations defined in glossary; RRR, NNT, and Cl calculated from data in article.

\section{COMMENTARY}

Hyperglycaemia is a frequent complication of critical illness, even in those who have not previously had diabetes. It is common practice to start insulin treatment after blood glucose concentrations reach about twice the normal value. However, this methodologically strong study by Van den Berghe $\mathrm{et} \mathrm{al} \mathrm{provides} \mathrm{substantiation} \mathrm{for} \mathrm{the} \mathrm{treatment} \mathrm{of}$ even mild hyperglycaemia. By using a simple and inexpensive insulin treatment aimed at strict maintenance of normal blood glucose values, mortality was reduced by more than $40 \%$ among ICU patients. According to the number needed to treat (NNT) in the table, this means that 29 patients would need to be given intensive insulin treatment in order to prevent 1 additional death in the ICU.

Strengths of this study include minimisation of bias through randomisation of patients to the 2 groups, blinding of outcome assessors, and adjustment of the insulin dose by a team of nurses and a physician who were not participating in clinical decisions.

Critical care nurses frequently measure blood glucose concentrations and make decisions about the need to seek medical intervention. This study provides important new evidence that supports a change in practice towards earlier and more aggressive treatment. Although there are likely to be substantial cost savings associated with reductions in length of ICU stay, ventilation days, dialysis, bloodstream infections, and critical illness polyneuropathy, increased resources will be required to implement intensive insulin treatment. Prior planning to ensure an adequate supply of infusion pumps, glucose monitors, and nursing staff to perform the additional monitoring and lab tests will be required. Point of care blood glucose analysis would be an advantage.

Nurses will need to monitor patients closely for signs of hypoglycaemia and implement more frequent blood sugar measurements when metabolic requirements change (eg, during changes in feeding patterns, use of vasoactive drugs, or cardiovascular instability). Insulin treatment can also influence serum electrolytes; careful electrolyte monitoring will be necessary.

Jan M Binnekade, RN Research Nurse, Department of Intensive Care Academic Medical Centre Amsterdam, The Netherlands 